\title{
Maternal smoking during pregnancy and lower respiratory tract illness in early life
}

\section{B TAYLOR AND J WADSWORTH}

Department of Child Health, University of Bristol, and Departments of Paediatrics and Community Medicine, St Mary's Hospital Medical School, London

SUMMARY In a national study of 12743 children maternal, but not paternal, smoking was confirmed as having a significant influence on the reported incidence of bronchitis and admission to hospital for lower respiratory tract illness during the first five years of life. Reported rates of admissions to hospital for lower respiratory tract diseases were found to be as high in children born to mothers who stopped smoking during pregnancy as in those whose mothers smoked continuously both during and after pregnancy. Rates of admissions to hospital for lower respiratory tract diseases in children whose mothers started smoking only postnatally were no higher than in those whose mothers remained non-smokers. Postnatal smoking seemed to exert a significant influence on the reported incidence of bronchitis, but less than smoking during pregnancy.

These findings suggest that maternal smoking influences the incidence of respiratory illnesses in children mainly through a congenital effect, and only to a lesser extent through passive exposure after birth.

Parental smoking has been incriminated as having a major adverse influence on the respiratory health of young children. ${ }^{1-6}$ Fergusson et al found that only maternal, and not paternal, smoking was influential. ${ }^{56}$ They suggested that fathers who smoked have less contact than mothers with young children, and so there is less irritation of the child's lower respiratory tract from passively inhaled smoke of paternal origin. There are other possible explanations. Maternal cigarette smoking during pregnancy is a health hazard to unborn children, affecting birth weight and predisposing to abortion; ${ }^{7-9}$ some studies have suggested that there is an increase in congenital abnormalities in children born to mothers who smoke. ${ }^{10-13}$

Smoking by the mother during pregnancy may cause a congenital predisposition in the child to subsequent respiratory illnesses; we investigated this possibility using data from a national birth cohort study.

\section{Subjects and methods}

CHES (the Child Health and Education Study) is a continuing survey of children studied neonatally in the British Births Survey. ${ }^{14} 15$ The cohort originally comprised all children born in the United Kingdom, including Northern Ireland, from 5 to 11 April 1970 inclusive. In 1975, 12743 children of the 16015 born in that week and living in England, Scotland, and Wales were traced $(79.6 \%)$. Health visitors interviewed the mothers at home and gathered over 500 items of information about social background, family, and health, including whether the child had had any episodes of bronchitis during the first five years, and whether the child had been admitted to hospital with a lower respiratory tract illness (wheezing, bronchitis, bronchiolitis, or pneumonia) and at what age.

At the interview in 1970 information had been gathered about the mother's smoking habit in pregnancy, the average number of cigarettes smoked each day, the time of giving up smoking if the mother was a previous smoker (recorded as months before delivery), as well as the child's birth weight and any neonatal problems. At the five year interview information was collected about the reported number of cigarettes, if any, smoked by each parent and the duration of regular smoking by each parent since the child's birth.

To allow for factors that could influence both smoking and respiratory illnesses the following 
information collected at the five year interview was included in multivariate analyses: sibling ranking at five years, the health visitor's assessment of the home equipment (luxurious, high standard or average, low, very low standard), whether the child had been breast fed, the number of times the family had moved house in the child's first five years, and the social index ${ }^{16}$ - that is a composite assessment of socioeconomic state including domestic crowding, parental education, tenure of accommodation, type of neighbourhood, and paternal occupation.

The social data obtained in 1970 were less extensive than those obtained in 1975 . The following factors were assessed: social class and mother's age, marital state, and length of full time education. Preliminary analysis included two way tabulations and $\chi^{2}$ calculations; for multivariate analyses logistic analysis of multiway contingency tables ${ }^{17}$ using the generalised linear interactive modelling statistical package $\mathrm{GLIM}^{18}$ was used to allow assessment of individual factors after simultaneous adjustment for all other factors in the model.

Where there were missing data (never more than $5 \%$ and usually less than $2 \%$ ) as complete a set as possible was used in the analysis. Thus the denominators used to obtain percentages in the tables exclude missing values.

\section{Results}

Initial cross tabulation showed that rates of lower respiratory tract illness in the children increased the more the mother smoked. This was so for smoking both during pregnancy and also subsequently (Figure). These dose response relations remained highly significant $(p<0.001)$ and were only slightly attenuated when allowance was made in multivariate analyses for the possible effects of birth weight, social index, home assessment, household moves, number of siblings, and breast feeding.

Tables 1 and 2 show the relations between respiratory illness in the children and parental smoking habits and confirms the findings of Fergusson et al. ${ }^{56}$ Data collected at five years were used

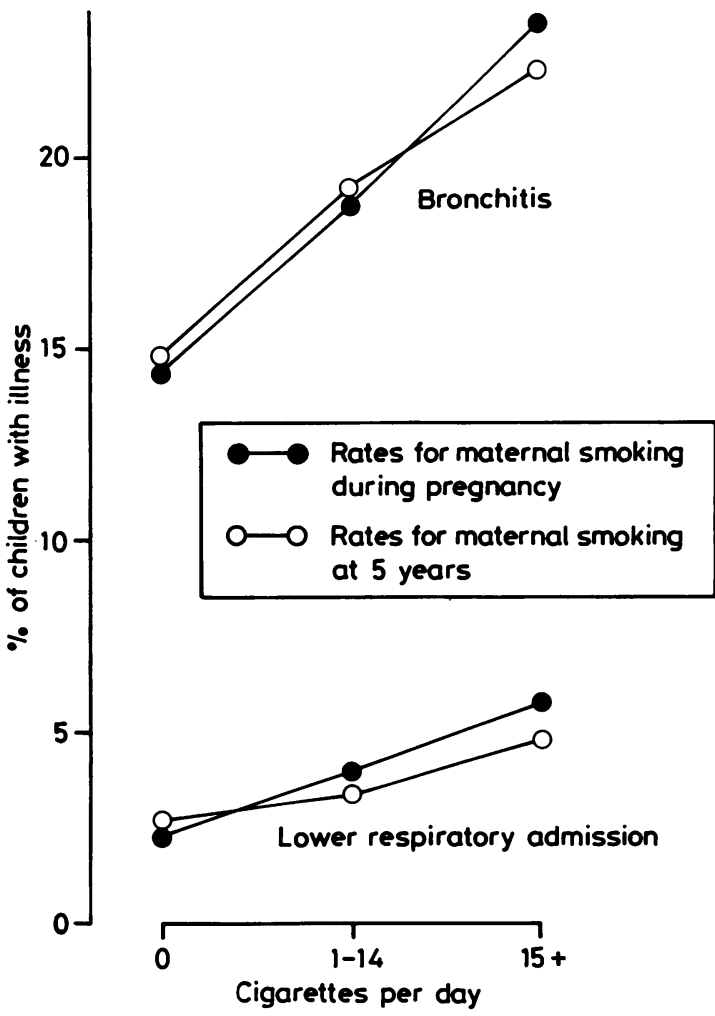

Figure Comparative effect of increasing levels of maternal smoking during and after pregnancy on risk of bronchitis and admissions for lower respiratory tract disease in children aged $0-5$.

for this analysis as information on paternal smoking was not collected at the 1970 interview. In general, rates of admissions to hospital for lower respiratory tract illnesses and bronchitis followed the trend of the mother's smoking rather than the father's, with the highest rates occurring in children whose mothers smoked most heavily, irrespective of the father's cigarette usage. Logistic multiway contingency table analysis confirmed this relation.

Table 1 Children aged 0-5 admitted to hospital with lower respiratory tract illness according to parental smoking habits

\begin{tabular}{|c|c|c|c|c|c|c|}
\hline \multirow{3}{*}{$\begin{array}{l}\text { Daily No of cigarettes } \\
\text { smoked by father }\end{array}$} & \multicolumn{6}{|c|}{ Daily No of cigarettes smoked by mother } \\
\hline & \multicolumn{2}{|l|}{ None } & \multicolumn{2}{|l|}{$1-14$} & \multicolumn{2}{|c|}{15 or more } \\
\hline & $\begin{array}{l}\text { No } \\
\text { studied }\end{array}$ & $\begin{array}{l}\% \text { Admitted } \\
\text { to hospital }\end{array}$ & $\begin{array}{l}\text { No } \\
\text { studied }\end{array}$ & $\begin{array}{l}\% \text { Admitted } \\
\text { to hospital }\end{array}$ & $\begin{array}{l}\text { No } \\
\text { studied }\end{array}$ & $\begin{array}{l}\% \text { Admitted } \\
\text { to hospital }\end{array}$ \\
\hline None & 5216 & $2 \cdot 7$ & 924 & $3 \cdot 0$ & 1096 & $5 \cdot 3$ \\
\hline $1-14$ & 804 & 2.9 & 473 & $3 \cdot 8$ & 299 & 8.4 \\
\hline 15 or more & 1559 & $2 \cdot 8$ & 770 & 3.4 & 1586 & $4 \cdot 5$ \\
\hline
\end{tabular}


Table 2 Children aged 0-5 with at least one episode of bronchitis according to parental smoking habits

\begin{tabular}{|c|c|c|c|c|c|c|}
\hline \multirow{3}{*}{$\begin{array}{l}\text { Daily No of cigarettes } \\
\text { smoked by father }\end{array}$} & \multicolumn{6}{|c|}{ Daily No of cigarettes smoked by mother } \\
\hline & \multicolumn{2}{|l|}{ None } & \multicolumn{2}{|l|}{$1-14$} & \multicolumn{2}{|c|}{15 or more } \\
\hline & $\begin{array}{l}\text { No } \\
\text { studied }\end{array}$ & $\begin{array}{l}\% \text { With episodes } \\
\text { of bronchitis }\end{array}$ & $\begin{array}{l}\text { No } \\
\text { studied }\end{array}$ & $\begin{array}{l}\% \text { With episodes } \\
\text { of bronchitis }\end{array}$ & $\begin{array}{l}\text { No } \\
\text { studied }\end{array}$ & $\begin{array}{l}\% \text { With episodes } \\
\text { of bronchitis }\end{array}$ \\
\hline None & 5039 & $14 \cdot 5$ & 893 & $19 \cdot 3$ & 1049 & $20 \cdot 9$ \\
\hline $1-14$ & 774 & $14 \cdot 0$ & 459 & $14 \cdot 4$ & 286 & $27 \cdot 3$ \\
\hline 15 or more & 1514 & $16 \cdot 2$ & 742 & $19 \cdot 0$ & 1520 & $22 \cdot 4$ \\
\hline
\end{tabular}

Maternal smoking had a significant influence $(p<0.01)$ on both admissions to hospital with lower respiratory tract illness and the incidence of bronchitis; paternal smoking had no significant influence on either condition when maternal smoking was taken into account.

There was an overall high collinearity between maternal smoking during pregnancy and postnatal maternal smoking assessed at five years: over $90 \%$ of women who smoked in pregnancy were still smoking when their children were 5 years old. To assess whether smoking during pregnancy influenced children's subsequent respiratory health independently of postnatal smoking it was necessary to identify mothers who changed their smoking habits before or after the birth of the study child and compare rates of respiratory illness in their children with those of the ones whose mothers smoked continuously or not at all.

Table 3 shows the rates of bronchitis and admissions to hospital for lower respiratory tract illness according to the mothers' smoking habits. Smoking

Table 3 Children aged 0-5 admitted to hospital with lower respiratory tract illness, or having bronchitis, according to mothers' smoking habits

\begin{tabular}{lcll}
\hline & $\begin{array}{l}\text { No } \\
\text { studied }\end{array}$ & $\begin{array}{l}\text { \% Admitted } \\
\text { to hospital }\end{array}$ & $\begin{array}{l}\% \text { With } \\
\text { episodes of } \\
\text { bronchitis }\end{array}$ \\
\hline Smoked continuously & 5629 & $4 \cdot 4$ & $20 \cdot 3$ \\
Smoked only during pregnancy & 493 & $5 \cdot 9$ & $18 \cdot 9$ \\
Smoked only after child was born & 353 & $3 \cdot 1$ & $18 \cdot 2$ \\
Never smoked & 5852 & $2 \cdot 3$ & $14 \cdot 1$ \\
\hline
\end{tabular}

during pregnancy, but stopping before the child was born, was associated with an increased incidence of all lower respiratory tract illnesses, but smoking only after the birth of the child had no obvious effect on admissions to hospital though an apparent effect on the incidence of bronchitis. Logistic analysis of these data confirmed the highly significant effect of smoking during pregnancy on both rates of admission to hospital $(p<0 \cdot 001)$ and incidence of bronchitis $(\mathrm{p}<0.01)$; postnatal smoking alone had no effect on admissions to hospital and a marginal, though not significant, effect on the incidence of bronchitis.

Because the effect of maternal smoking on children's respiratory health is most obvious in early life, ${ }^{6}$ and because our information about postnatal smoking was collected when the children were 5 years old, the effect of varying duration of postnatal smoking was examined. Rates of admissions to hospital were not influenced, with smoking during pregnancy remaining highly significant $(\mathrm{p}<0.001)$ and duration of postnatal smoking having no significant effect. Rates of bronchitis, however, were found to be highest in children whose mothers smoked both during pregnancy and for most or all of the time from birth to age 5. Significant and independent effects from both smoking during pregnancy $(\mathrm{p}<0.001)$ and postnatal smoking $(p<0.05)$ were found on logistic analysis. More than $10 \%$ of the information on the duration of postnatal smoking was missing, however, so these results must be assessed with caution.

The mothers were compared for marital state, social class, length of full time education, and age at

Table 4 Social data (1970 survey) on mothers according to their smoking habits

\begin{tabular}{lllll}
\hline & $\begin{array}{l}\text { No } \\
\text { studied }\end{array}$ & $\begin{array}{l}\% \text { In social } \\
\text { classes 4 and 5 }\end{array}$ & $\begin{array}{l}\text { \% Who left } \\
\text { school aged <l6 }\end{array}$ & $\begin{array}{c}\text { \% Unmarried } \\
\text { under 20 }\end{array}$ \\
\hline Smoked continuously & 5629 & $26 \cdot 0^{*}$ & $74 \cdot 9^{*}$ & $7 \cdot 4$ \\
Smoked only during pregnancy & 493 & $15 \cdot 1$ & $62 \cdot 4$ & $7 \cdot 7$ \\
Smoked only after child was born & 353 & $18 \cdot 3$ & $64 \cdot 0$ & $7 \cdot 6$ \\
Never smoked & 5852 & $18 \cdot 5$ & $58 \cdot 4$ & $12 \cdot 3$ \\
\hline
\end{tabular}

*Significantly different from other values in column $\left(\mathrm{p}<0.001\right.$, partitioned $\chi^{2}$ analysis $)$. 
Table 5 Percentage of children admitted with lower respiratory tract illness in different age groups according to mothers' smoking habits

\begin{tabular}{|c|c|c|c|c|c|c|}
\hline $\begin{array}{l}\text { Age at } \\
\text { admission } \\
\text { (months) }\end{array}$ & $\begin{array}{l}\text { Mother smoked } \\
\text { during pregnancy } \\
(n=6 / 22)\end{array}$ & $\begin{array}{l}\text { Mother did not } \\
\text { smoke during } \\
\text { pregnancy } \\
(n=6205)\end{array}$ & p Value & $\begin{array}{l}\text { Mother smoked } \\
\text { when child } \\
5 \text { years old } \\
(n=5982)\end{array}$ & $\begin{array}{l}\text { Mother did not } \\
\text { smoke when child } \\
5 \text { years old } \\
(n=6.345)\end{array}$ & $p$ Value \\
\hline$<12$ & $2 \cdot(17$ & 0.93 & $<0 \cdot(00) 1$ & 2.119 & 0.95 & $<0 \cdot(00) 1$ \\
\hline $12-35$ & 1.83 & $1 \cdot 05$ & $<0.001$ & 1.76 & $1 \cdot 13$ & $<0 .(01$ \\
\hline $35-59$ & $1 \cdot 14$ & 0.68 & $<0.01$ & 1.05 & 0.77 & NS \\
\hline
\end{tabular}

delivery (Table 4). Continuous smokers differed from non-smokers for each of these factors, but those who stopped smoking before birth and those who started smoking postnatally did not differ significantly from each other on partitioned $\chi^{2}$ analyses. Mothers who smoked continuously differed significantly from the other three groups in social class and educational attainment; non-smokers differed from the other three groups for marital state and age at child's birth. It seems unlikely, therefore, that variation in socioeconomic factors among the four smoking groups explains our results, nor did there seem to be an unexpected effect from paternal smoking: rates of illness in the children among the four groups did not vary significantly when patterns of paternal smoking were considered.

The age at which bronchitis occurred was not known, but the age at admission to hospital for lower respiratory conditions was. Table 5 shows the effect of maternal smoking habits on rates of hospital admission at different age periods during the first five years. Children with repeated admissions were counted only once during each age period. Maximum differences between admission rates for children of smoking and non-smoking mothers occured during the first year of life. There was, however, still a significant difference up to the age of 3 years, and this trend continued up to 5 years. Although there was high collinearity between the two assessments, smoking during pregnancy (those who smoked continuously and those who stopped during pregnancy) had a significantly more persistent effect than subsequent smoking (those who smoked continuously plus those who took up smoking after the birth).

\section{Discussion}

These results, as well as confirming previous studies that have shown that parental smoking has a harmful effect on children's respiratory health. ${ }^{1-6}$ suggest that smoking during pregnancy may have a more important and independent effect on the risk of lower respiratory illness in children than passive exposure to smoking after birth. None of the previous studies on parental smoking and respiratory illness in children has considered a congenital effect from maternal smoking in pregnancy; because of the size and range of CHES, however, it has been possible to examine the effects of both smoking and changing smoking habits. With the application of log linear modelling techniques we were able to assess the prenatal and postnatal components of the overall effect of smoking on children's respiratory illness. In the light of these results earlier studies and their recommendations may require reappraisal.

Rates of admission to hospital for lower respiratory illnesses at least once during the first five years of life were as high in children whose mothers smoked at some time during pregnancy but who stopped before delivery and did not then smoke postnatally as in children whose mothers smoked in pregnancy and continued to smoke after the birth of the child. Rates of admission to hospital remained low when mothers who did not smoke during pregnancy began smoking subsequently. Smoking after birth did not influence rates of admission to hospital independently of smoking during pregnancy. As far as bronchitis during the first five years of life was concerned, smoking during pregnancy had a major effect, but postnatal smoking also seemed to influence rates of illness. Although rates of bronchitis were higher in children of mothers who smoked only during pregnancy and not subsequently than in children whose mothers never smoked, the highest rate of bronchitis was seen in children whose mothers smoked both during pregnancy and during the children's first five years. The need for admission to hospital probably reflects more serious respiratory disease than does reported bronchitis.

The findings concerning the level of maternal smoking support our overall conclusions. Mothers who continued to smoke tended to smoke more with time. Only $30.4 \%$ of these mothers were heavy smokers (15 or more cigarettes a day) during pregnancy, whereas $50.5 \%$ were five years later. Only $15.0 \%$ of those who stopped smoking had been heavy smokers, compared with $27.7 \%$ of those who started smoking postnatally. Thus heavier postnatal 
smoking did not overcome the apparent harmful effect of smoking during pregnancy.

Rates of admission to hospital were highest in children of mothers who smoked during the first year of life (Table 5). Although there was a strong correlation between the two measures, smoking assessed during pregnancy seemed to have a more persistent effect than postnatal smoking assessed five years later.

These findings suggest that smoking during pregnancy may cause congenital damage to the developing respiratory system, either the bronchial tree or the developing lung vasculature, as has been shown in the umbilical vessels. ${ }^{19}$ An alternative explanation for the apparent effect of smoking during pregnancy is that some interference with the immune system might predispose to respiratory infections - a secondary congenital immunodeficiency. Cigarette smoking is immunosuppressive both in vivo and in vitro. ${ }^{20}$ Datau et al described abnormalities of polymorphonuclear leucocyte function in children of parents who smoke, ${ }^{21}$ and Paganelli et al showed an abnormality in immune function in cord blood from mothers who smoke. ${ }^{22}$

Cigarette smoking during pregnancy has been associated with reduced birth weight, and low birth weight is associated with a wide range of defective immune functions that might predispose to respiratory infection. ${ }^{23}$ Low birth weight, although showing a highly significant correlation with rates of both admission to hospital and bronchitis, had its effect independent of maternal smoking.

An additional observation concerns the rate of lower respiratory illness in the offspring of teenage mothers in our study population. These children for various social, environmental, and biological reasons might have been expected to have a high rate of lower respiratory tract illness; they were more likely than children born to older mothers to have low birth weights, to have unmarried mothers of low educational attainment and low social class, to live in poor neighbourhoods, to move frequently, and to have more siblings at the age of 5. Their mothers were more likely than older mothers to be smokers and to be heavy smokers (15 or more cigarettes a day) when the children were 5 years old. These children were, however, no more liable than children of older mothers to bronchitis or to be admitted to hospital. ${ }^{24} \mathrm{~A}$ possible explanation for these paradoxical results was the finding that although teenage mothers were more likely to smoke some cigarettes during pregnancy, they were less likely than older mothers to be heavy smokers during this time, especially those who were under 18 years old when their children were born. Rates of respiratory illness across the whole maternal age range in general followed rates of smoking during pregnancy and not postnatal smoking. ${ }^{25}$

Many of the data used in this study were collected retrospectively, and so variable maternal recall might have influenced the findings. The large sample size and representativeness of the study population, however, should reduce this effect. The data also reflected the current habits, and are consistent both for reported bronchitis and the more objective variable of admission to hospital. Adequate agreement was found between medical data and parental reports of lower respiratory tract illness resulting in consultations with general practitioners ${ }^{2}$ and hospital admission, ${ }^{26}$ even though there may be variation between the two sources in exactly what names the respiratory conditions are given. ${ }^{27}$ The data used in the present analysis were collected in 1970 and 1975, before there was widespread appreciation of the possible ill effects of parental smoking on children's respiratory health; the questions are thus likely to have been honestly answered.

The accumulated evidence suggests that, whatever the mechanism, exposure to cigarette smoke is bad for children during both intrauterine and subsequent life.

We are grateful to Professor N R Butler and Professor J R T Colley for their comments on drafts of this paper. The CHES five year follow up was funded by a project grant from the Medical Research Council to the department of child health of the University of Bristol. Additional financial support came from Action for the Crippled Child and the National Birthday Trust Fund. We gratefully acknowledge the cooperation of the area health authorities, health boards, and health visitors throughout England, Scotland, and Wales and the contributions of previous CHES survey workers to the research. BT and JW (in part) were supported in Bristol by the Riyadh Al Kharj Hospital Programme. Saudi Arabia.

\section{References}

1 Harlap S, Davies AM. Infant admissions to hospital and maternal smoking. Lancet 1974;i:529-32.

2 Colley JRT, Holland WW, Corkhill RT. Influence of passive smoking and parental phlegm on pneumonia and bronchitis in carly childhood Lancet 1974:ii:1031-4.

' Leeder SR, Corkhill R. Irwig LM, Holland WW. Colley JRT. Influence of family factors on the incidence of lower respiratory illness during the first year of life British Journal of Preventive and Social Medicine 1976;30:203-12.

4 Rantakillio P. Relationship of maternal smoking to morbidity and mortality of the child up to the age of five. Acta Paediatr Scand 1978;67:621-31.

5 Fergusson DM, Horwood LJ, Shannon FT. Parental smoking and respiratory illness in infancy. Arch Dis Child 1980:55: $358-61$.

" Fergusson DM. Horwood LJ. Shannon FT. Taylor B. Parental smoking and lower respiratory illness in the first three years. J Epidemiol Community Health 1981;35:18()-4.

7 Simpson WJ. A preliminary report on cigarette smoking and the incidence of prematurity. Am J Obstet Gynecol 1957:73:808-15. 
* Butler NR, Goldstein H, Ross EM. Cigarette smoking in pregnancy: its influence on birthweight and perinatal mortality. Br Med J 1972;ii:127-30.

" Kline J. Stein ZA. Susser M, Warburton D. Smoking: a risk factor for spontaneous abortion. N Engl J Med 1977;297:793-6.

11) Fedrick J. Alberman ED. Goldstein H. Possible teratogenic effect of cigarette smoking. Nature 1971;231:529-30.

1 Himmelberger DU, Brown BW, Cohen EN. Cigarette smoking during pregnancy and the occurrence of spontaneous abortion and congenital abnormality. Am J Epidemiol 1978;108:47(0-9.

12 Evans DR, Newcombe RG. Campbell H. Maternal smoking habits and congenital malformations. A population study. $\mathrm{Br}$ Med J 1979;2:171-3.

13 Christianson RE. The relationship between maternal smoking and the incidence of congenital anomalies. Am J Epidemiol 1980;112:684-95.

${ }^{14}$ Chamberlain R. Chamberlain G, Howlett B, Claireaux A. British births 1970. Vol 1. The first week of life. London: Heinemann, 1975.

15 Chamberlain G. Phillipp E. Howlett B. Claireaux A. British births 1970. Vol 2. Obstetric care. London: Heinemann, 1978.

${ }^{16}$ Osborn AF, Morris AC. The rationale for a composite index of social class and its evaluation. Br J Sociol 1978:30:36-60.

${ }_{17}$ Everitt BS. The analysis of contingency tables. London: Chapman and Hall, 1977.

If Baker RJ, Nelder JA. Generalised linear interactive modelling system. London: Royal Statistical Socicty, 1977.

19 Asmussen I. Fetal cardiovascular system as influenced by maternal smoking. Clin Cardiol 1979;2:246-56.

20) Holt PG, Keast D. Environmentally induced changes in immunological function: acute and chronic effects of inhalation of tobacco smoke and other atmospheric contaminants in man and experimental animals. Bacteriology Reviews 1977:41: $205-16$

21 Datau G, Corberand J, Enjaume C. Rochiccioli P. Inhalation passive de fumée de tabac ches l'enfant prescolaire. Etude clinique et biologique. Revue Francaise de Maladies Respiratoires 1978;6:549-53.

22 Paganelli R, Ramadas D, Layward L, Harvey BAM, Soothill JF. Maternal smoking and cord blood immunity function. Clin Exp Immunol 1979:36:256-9.

${ }^{23}$ Chandra RK. Fetal malnutrition and postnatal immunocompetence. Am J Dis Child 1975;129:450-4.

${ }^{24}$ Taylor B. Wadsworth J. Butler NR. Teenage mothering; admission to hospital, and accidents during the first five years. Arch Dis Child 1983;58:6-11.

${ }^{25}$ Taylor B. Social factors and related influences on lower respiratory illnesses of early childhood. Respiratory Disease in Practice 1983;1:30-35.

26 Fergusson DM, Horwood LJ, Shannon FT, Taylor B. Breast feeding, gastrointestinal and lower respiratory illness in the first two years. Aust Paediatr J 1981:17:191-5.

27 Watkins CJ, Burton P, Leeder S, Sittam PY, Wever AMJ, Wiggins R. Doctor diagnosis and maternal recall of lower respiratory illness. Int J Epidemiol 1982;11:62-6.

Correspondence to Dr B Taylor, Department of Paediatrics, St Mary`s Hospital Medical School, London W2 1PG.

Received 27 February 1987

\section{Editorial Committee}

Members of our Editorial Committee usually serve for five years. We thank Dr A S Hunter a:nd Professor J S Wigglesworth, who have retired from the Committee, for their excellent work on behalf of the Journal.

We welcome as new members Dr M J Dillon, Consultant Nephrologist, Hospital for Sick Children, London; Dr I M Hann, Consultant Haematologist, Royal Hospital for Sick Children, Glasgow; Dr J W Keeling, Consultant Pathologist, John Radcliffe Hospital, Oxford, and Dr J F N Taylor, Hospital for Sick Children, London. 